\title{
A FORMA RACIONAL DE VIDA “PREENCHIDA” PELA SUBJETIVIDADE PESSOAL
}

\section{THE FULFILLMENT OF THE RATIONAL FORM OF LIFE TROUGH THE PERSONAL SUBJECTIVITY}

Marcelo Fabri*

\begin{abstract}
RESUMO
O artigo procura apresentar o conceito husserliano de forma racional de vida a partir da relação entre teoria e práxis. Contrapõe dois momentos da reflexão de Husserl sobre a razão prática (1908-14 e 1920-24). Se, no primeiro momento, o filósofo sublinha que a Filosofia é a ideia de um conhecimento perfeito, presente até mesmo pelas ciências particulares, no segundo a Filosofia é descrita por uma espécie de subordinação à Ética, entendida como rainha das ciências técnicas. Ora, o que une esses dois momentos aparentemente inconciliáveis é o recurso à subjetividade pessoal, capaz de oferecer à forma vazia de vida racional um conteúdo fático e particular, aqui e agora. O imperativo formal ("escolhe a forma racional de vida") se preenche graças à matéria fornecida pelas atividades pessoais, no tempo.
\end{abstract}

PALAVRAS-CHAVE: fenomenologia, ética, subjetividade, teoria, práxis

\begin{abstract}
This essay seeks to introduce Husserl's concept of rational form of life trough the relation between theory and praxis. It compares two moments of reflection in Husserl's work regarding the practical reason (1908-14 and 1920-24). If, on one hand, he highlights that Philosophy is the idea of a perfect knowledge which is found even in particular sciences, on the other hand Philosophy is described as subordinated to ethics -which is known as the ultimate of technical sciences. What brings these two apparently opposite moments together is the usage of a personal subjectivity, capable to offer a factual and particular content - the here and now - to an empty form of rational life. Thanks to the matter provided by personal activities, through time, the formal imperative ("choose the rational form of life") is fulfilled.
\end{abstract}

KEYWORDS: phenomenology, ethics, subjectivity, theory, praxis

\footnotetext{
* Professor do departamento de Filosofia da UFSM (fabri.ufsm@gmail.com)
} 


\section{Introdução}

Husserl sempre se mostrou interessado em associar a Filosofia à forma racional de vida, unindo com esta expressão duas dimensões da tarefa do pensamento: a teoria e a práxis. Para o leitor, há sempre o embaraço de ter de interpretar essa proposta (aparentemente ambígua) ora escorregando para o intelectualismo inevitável de uma filosofia que se propõe "científica", ora se deixando encantar pela "descoberta" do mundo da vida, pelo papel da vida sensível na fundamentação do conhecimento, pela importância da intersubjetividade na constituição do mundo objetivo, etc. Perda do mundo ou redescoberta do mundo? De nossa parte, pensamos ser fundamental perguntar se o método fenomenológico não representa uma abertura ao mundo concreto da pessoa humana, propiciada pelo próprio rigor inerente a este método. Como assim? É que o pensamento de Husserl, mesmo em sua obstinação por considerar a Filosofia como ciência dominada por um interesse puramente teórico, não deixa de ser uma defesa da forma racional de vida a partir do reconhecimento da singularidade de subjetividades humanas concretas. Assim, a Filosofia como ciência rigorosa ou de essências só se efetiva se tiver olhos ou ouvidos para a originalidade das escolhas e das realizações pessoais. O interesse puramente teórico, próprio da Filosofia, serve como guia e fundamento para todas as formas possíveis de saber científico, até mesmo para uma ciência da razão prática. No entanto, esta primazia do saber teórico não pode, paradoxalmente, prescindir de uma ciência envolvida com a práxis. A filosofia se submete, ao final das contas, a um interesse prático, uma vez que depende de pessoas humanas reais tentando realizar, a partir de sua própria singularidade e unicidade, a forma racional de vida.

Para sustentar essa tese, confrontamos dois momentos da argumentação de Husserl sobre a relação entre razão teórica e razão prática. Primeiramente, o filósofo destaca o primado da razão lógica para tratar assuntos ligados à ética. Na ideia de Filosofia, por exemplo, há que se levar em conta a tendência a um conhecimento sistemático, perfeito e absoluto que entrelaça e abarca todas as formas de consciência submetidas à consideração racional. As leis lógicas fornecem as normas para todo pensamento, até mesmo para a consciência envolvida com assuntos práticos. Nas Lições sobre e ética e teoria do valor (1908-14) a ideia de conhecimento perfeito, da qual as ciências particulares não podem prescindir, determina a ideia de consciência perfeita e de mundo perfeito, consideradas pela ética. 
Tudo parece mudar com a obra Introdução à Ética (1920-24), na qual Husserl afirma que a Ética como disciplina técnica abarca a ideia de Filosofia. O verdadeiro guia da busca teórica não é a verdade em geral, mas a unidade de um fim prático, a unidade de uma teoria universal e racional. Isto significa dizer que a ideia de perfeição não depende apenas do ideal de um conhecimento perfeito, mas também e, sobretudo, da aspiração moral a um fim prático que, para um indivíduo, se apresenta como dever absoluto. O movimento para a ideia é algo humano, demasiado humano. A singularidade da pessoa não se dissolve num universal sem rosto, pois somente tal singularidade poderia fazer do ideal uma realidade, dando-lhe uma expressão concreta, no aqui e agora. O imperativo formal se preenche, então, graças à matéria fornecida pelas atividades pessoais, no tempo.

\section{A Filosofia como ideia de conhecimento perfeito e absoluto}

Comecemos procurando entender o que significa pensar a Filosofia como ideia caracterizada por um interesse puramente teórico. O que distingue o labor filosófico daquele realizado pelas demais ciências e saberes? O que distingue uma ciência filosófica de uma ciência não-filosófica, e mesmo da pré-filosófica? A resposta está no impulso que move a referida atividade, a saber, a ideia de um conhecimento perfeito e absoluto, conhecimento que não pode prescindir da Ciência em sentido grego (Aristóteles), isto é, movida por uma aspiração puramente teórica. Mesmo que tal ideia seja, no início, confusa e obscura, todos os outros conhecimentos irão, de algum modo, submeter-se a ela. Vale lembrar que nenhum conhecimento particular poderia satisfazer as exigências inerentes à ideia da qual recebem sua orientação. Todos os conhecimentos particulares dependem de princípios e de disciplinas puramente teóricas, bem como das normas ideais que elas determinam. Eis por que todos os conhecimentos particulares sempre podem ser integrados a conhecimentos filosóficos, ou seja, encontram um lugar no caminho que deve conduzir ao ideal do conhecimento absoluto e perfeito, que é a Filosofia. Neste sentido, em toda aspiração teórica já se encontra a tendência, mesmo que não explícita, ao conhecimento perfeito. Por quê? Porque as formas científicas de conhecimento não deixam de ser uma inevitável busca de distinção, de clareza, de justificação, bem como uma luta para superar todo isolamento e toda particularidade. Nas palavras do filósofo: "a unidade do conhecimento teórico estende seu poderio sempre mais longe, de domínio em domínio, ilimitadamente” (HUSSERL, 2009, p. 249). 
Por conseguinte, todo interesse teórico traz em si, ainda que de modo dissimulado, a busca de um objetivo que Husserl irá chamar de suprema unificação. Em cada movimento direcionado a um conhecimento teórico, há uma luta constante para se afastar a dispersão e a fragmentação. O que se aspira, ao final das contas, é um progresso sistemático, é o saber unificado e apto a ser elucidado à luz da evidência (HUSSERL, 2009, p. 250). Tomada em sua facticidade histórica, uma ciência não se deixa ver apenas como um estado atual de realização, mas também e, sobretudo, como tendência a uma realização e a um acabamento mais perfeitos. Assim, ao lado da ciência como fato, pode-se visar à ideia de realização perfeita, à ideia de uma realização plena da ciência (MURAULT, 1987, p. 17). Todo esforço para se conhecer cientificamente tende a esta ideia de perfeição, e isto de um modo vital. Se as ciências da natureza manifestam uma preocupação com o ser real, com o aqui e agora do mundo natural (fins vitais contingentes), nem por isso elas deixam de se vincular à ideia de unidade, de sistematicidade, de verdade, numa palavra, de manifestar, de algum modo, a aspiração ao ideal de um conhecimento puramente teórico, isto é, um conhecimento determinado pelos valores que residem no próprio conhecimento (HUSSERL, 2009, p. 250).

Eis por que o interesse teórico deverá abarcar não apenas os conhecimentos relacionados às ciências, de modo geral, mas também tudo aquilo que diz respeito ao agir e ao valorar presentes em situações humanas concretas. Também nossas experiências com valores passarão pelo crivo da razão lógica, uma vez que nossos juízos sobre valores podem, eles também, estar dotados de verdade, ou de falsidade. Não fosse assim, não teríamos como sustentar que a racionalidade e seu contrário, a não-racionalidade, estão presentes em nossas ações ou nos bens que escolhemos. Valorar e agir são intencionalidades que lançam os sujeitos na vida racional ou dela os afastam, dependendo da verdade ou falsidade que eles expressam. Há, portanto, ao lado das ciências da natureza as assim chamadas ciências axiológicas, cujos objetos são os valores, e não coisas naturais (HUSSERL, 2009, p. 254). Por via de consequência, se a ideia de Filosofia está presente, ainda que de modo inconsciente, em todas as ciências, as próprias ciências axiológicas estarão submetidas ao ideal de conhecimento sistemático, de unidade suprema do conhecimento. Para o filósofo, fica o desafio de mostrar qual o papel da axiologia na tendência a esta unidade ${ }^{1}$.

\footnotetext{
1 A esse respeito, o leitor fará bem em consultar a Segunda Seção das Lições sobre ética e teoria do valor (1914), intitulada Axiologia Formal (HUSSERL, 2009, p. 149-184). Como pesquisa crítica rigorosa e detalhada, vale conferir, de Beatrice Centi, o artigo sobre o conceito de valor nas Lições de 1914 (CENTI, 2004, p. 255$325)$.
} 
Eis o que consideramos fundamental explicar, acompanhando as reflexões detalhadas e rigorosas de Husserl, em suas Lições de ética e teoria do valor (1908-14). Ora, à primeira vista, a submissão de todas as ciências ao ideal de unidade inerente ao conceito de filosofia traz como consequência a radical dissociação entre teoria e práxis, mais precisamente, entre filosofia teórica e ética. Tudo se passa como se a reflexão sobre a razão prática fosse algo secundário em relação a uma tarefa puramente epistemológica, que nada tem que ver com a realidade concreta da vida ou, pelo menos, que nada diz sobre a função humana da própria ciência. Certo, privilegia-se a tendência ao ideal de perfeição de um conhecimento sistemático. Mas eis que Husserl nos surpreende ao recorrer a Kant para afirmar que os conhecimentos de fatos inserem as ciências da natureza numa espécie de teleologia construtiva, ou ainda, que o conhecimento dos fatos naturais se integra não apenas a um sistema abstrato de proposições, mas também ao ideal axiológico do conhecimento humano. A natureza, mais do que conjunto de fatos submetidos a leis, mostra uma notável virtude teórica (HUSSERL, 2009, p. 257), tendo em vista sua correspondência ao ideal de conhecimento já mencionado.

A passagem de uma visão da realidade como mundo de fatos para as idealizações e unificações que se constroem sistematicamente não aponta apenas para frias formalizações, uma vez que toda formalização, que colabora para a realização paulatina do ideal de conhecimento perfeito, deve inserir-se numa unidade que ultrapassa toda fragmentação. Intencionar o ideal de perfeição puramente teórico, situação que se dá inconscientemente em nossas realizações científicas voltadas a fins temporais, implica reconhecer que a consciência que conhece é, ao mesmo tempo, a consciência que realiza valorações e volições. Quanto mais nos voltamos para a ideia formalmente universal de uma natureza em geral, mais nos damos conta da aspiração à perfeição suprema, mais podemos lidar com puras possibilidades com respeito à natureza e ao mundo. Podemos, igualmente, nos ocupar de nossas próprias valorações, ou seja, podemos nos dirigir a elas, perguntando sobre o significado da perfeição relacionada à valoração. Nas palavras de Husserl: "Correlativamente, realidade absolutamente perfeita e consciência valorativa absolutamente perfeita se requerem mutuamente" (2009, p. 250).

Mas não nos enganemos: No período que antecede a Primeira Guerra Mundial (nossa referência é o escrito de 1911), Husserl não está defendendo uma submissão do interesse puramente teórico a uma consciência valorativa e prática, preocupada com realizações possíveis na realidade de fato. Trata-se de compreender a analogia entre a ideia de um 
conhecimento perfeito, no âmbito de uma pura reflexão teórica, à ideia de um mundo absolutamente perfeito que, por sua vez, clama pela ideia de uma personalidade absolutamente perfeita, bem como de uma vida que possa corresponder a tal personalidade. Trata-se de poder pensar tal vida, tal perfeição, tal subjetividade. Ou ainda: trata-se de considerar tudo o que é finito e factual a partir da ideia de conhecimento perfeito, cujo ápice não é outro senão a ideia de divindade, de ser absolutamente perfeito, de personalidade absolutamente perfeita. Sendo assim, não é o interesse teórico que depende da ideia de Deus, e sim o contrário. Considerada de uma perspectiva puramente ideal, a ideia de Deus remete à relação entre a consciência e o ser, entre o pensamento e aquilo que é pensado (Aristóteles). Mas, eis o que é fundamental considerar: a ideia absoluta não aponta para um "além" do mundo, para uma transcendência, mas sim para a perfeição ideal que emerge do processo imanente realizado por consciências humanas no interior do mundo (HUSSERL, 2009, p. 261).

\section{Em qualquer ciência estamos no reino da práxis}

Chegamos ao problema, ou à pergunta, que nos permite voltar os olhos para o outro lado de uma mesma moeda: como pensar o papel das consciências humanas na realização deste ideal? Dito de outro modo: qual o papel das subjetividades pessoais na realização da ciência? Certo, a ideia de um conhecimento perfeito não pode confundir-se com nenhuma prática científica direcionada ao ser real. A verdade é uma ideia, ou seja, é uma inteligibilidade que, mesmo sendo visada ou "descoberta" por indivíduos humanos concretos, em um contexto histórico específico, ultrapassa esses indivíduos, épocas e vivências. Não se pode fundar a verdade sobre a constituição da espécie humana (HUSSERL, 2014, § 51, p. 141). No caso da ética, que pode ser pensada a partir de proposições puramente formais com respeito ao agir correto, aos fins justos, etc., vale também esta submissão do normativo ao teórico, isto é, nenhuma situação de fato poderia negar a validade incondicional dos princípios teóricos relacionados ao valorar e ao agir. "Nenhuma proposição relativa à possibilidade da realização prática afeta o círculo das simples normas da valorização ética” (HUSSERL, 2014, $\S 16$, p. 37).

Ou seja, nenhuma inviabilização prático-real desmente a validade incondicional da razão prática, pensada do ponto de vista puramente formal e teórico. No entanto, o ideal de conhecimento perfeito depende de consciências humanas no tempo, mesmo não extraindo sua 
verdade dessas situações de fato. Vale, então, a pergunta: não são as subjetividades pessoais que sustentam, mantêm e reativam o interesse teórico? Valorações, decisões, ações não são atos de uma consciência em geral, mas condição imprescindível na formação de uma personalidade ao longo do tempo. Somente uma subjetividade pessoal poderia eleger, em algum momento de sua formação, a vida teórica como valor supremo. A normatividade e a verdade, que dependem da legislação formal da lógica, não podem decidir sobre o valor da própria ideia da ciência. A ética, neste caso, é uma disciplina técnica que diz respeito ao agir justo, e tal agir, por sua vez, não se separa da pergunta pelos fins justos que se devem perseguir, em determinada situação. Eis por que é sempre a subjetividade pessoal que poderá se perguntar pelo dever em sentido absoluto. Somente tal subjetividade poderia reconhecer, na atividade profissional puramente teórica, o dever incondicional relacionado à sua própria vida (HUSSERL, 2009 a, § 2, p. 10). Sempre que estejam em questão um querer e um agir, há um dever absoluto a ser considerado. Isto pode ser formalmente compreendido, antes mesmo de se colocar em questão o conteúdo do dever.

Esta argumentação conduz Husserl a um acerto de contas com a dimensão prática ou técnica da ciência. Pois cabe a uma disciplina técnica lidar com os bens práticos que, em dada situação, emergem como um dever (normativo) absoluto, seja do ponto de vista da subjetividade pessoal, seja da perspectiva social, ou da comunidade. Ora, as disciplinas práticas ou técnicas se diferem das disciplinas teóricas (matemática, física, química, biologia, ciências da linguagem, etc.) por estarem direcionadas a fins práticos. Elas não se fazem com vistas ao puro interesse teórico, mas preocupadas em aplicar certos conhecimentos num determinado setor da realidade. É assim que um engenheiro se beneficia de conhecimentos da matemática, da física, da química com um propósito técnico bem definido que, por exemplo, pode ser a construção de um edifício ou de uma estrada.

Nesse sentido, é fundamental perguntar: o que acontece quando um profissional da construção se beneficia de conhecimentos puramente teóricos transformando-os ou transfigurando-os num âmbito prático? Ele confere uma função prática a esses conhecimentos. As proposições puramente teóricas são como que transpostas para o âmbito prescritivo da instrução prática. Ordens, propósitos, conselhos, instruções: nada disso é um mero juízo ou proposição teórica. Por que, então, chamar uma disciplina prática de ciência? O sentido de verdade, aqui, não diz respeito às conexões puramente científicas de uma ciência teórica, e sim ao escopo prático, à unidade de um fim prático. Julgar de modo correto do 
ponto de vista lógico-formal é algo bem diferente de uma instrução "verdadeira" relacionada à construção de um edifício.

Para Husserl é verdadeiro de modo a priori que toda proposição teórica possa ser reconsiderada em sentido prático, ou seja, pode assumir uma função prática qualquer. Mas vale também o inverso: toda proposição prática pode ser compreendida em sentido teórico. $\mathrm{O}$ exercício de uma profissão técnica pode, portanto, converter-se em discussão puramente científica sobre tal atividade, tal como ocorre na jurisprudência, por exemplo. O que está em jogo é a possibilidade de direito de que as disciplinas técnicas adquiram o status de ciência. Ou seja, também as disciplinas técnicas possuem em seu núcleo o âmbito teórico que permite defini-las como científicas. Podemos, então, compreender que o domínio prático é mais do que uma área dominada por prescrições práticas sem implicações científicas. Podemos, em suma, tomar a esfera prática de uma perspectiva puramente teórica, abordando as verdades teóricas de seu âmbito específico. Fazemos teoria da práxis, e isso pode se tornar fundamental para o próprio exercício de uma profissão técnica.

Ora, não voltamos ao ponto de partida: no fundo é o interesse teórico que deve dirigir? A ética não deve ser fundada cientificamente para se tornar uma ciência prática do agir humano? O interesse teórico não unifica todas as ciências a partir da unidade da Filosofia? Todo aquele que se dedica ao conhecimento na dimensão pura da teoria, já se desprendeu das preocupações técnicas e prescritivas das atividades correspondentes, uma vez que sua atenção recai sobre o juízo ou proposições consideradas teoricamente. Mas, eis que há o outro lado da mesma moeda: o julgar e o conhecer racionais implicam uma vida que julga e, sendo assim, podem ser vistos como mediadores de um desejo, de um esforço, de um querer! Mesmo a razão lógica, afirma Husserl, é razão prática (HUSSERL, 1998, § 15, p. 143). Não que julgar e querer sejam sinônimos. Longe disso. O valorar, o querer, o desejar, o agir, na medida em que são direcionados a juízos e verdades teóricos, não se identificam ao ato judicativo enquanto tal. Um juízo teórico não é verdadeiro porque quero ou desejo que o seja. E, no entanto, o questionamento teórico é um comportamento prático relacionado a juízos. Estamos diante de um esforço prático que, no caso, está às voltas com uma decisão com respeito ao juízo (Ibid., p. 144).

Se, em suas Lições de ética e teoria do valor, Husserl destacava o interesse puramente teórico a partir da tendência ao conhecimento perfeito, subordinando a ética como disciplina prática a este ideal normativo, na obra Introdução à Ética (1920-24), seu enfoque e sua ênfase passam a ser algo bem diferente. Certo, a Filosofia pode ser vista como ideia de um 
conhecimento perfeito, de ciência puramente teórica. No entanto, na medida em seu objetivo é a unidade de uma teoria racional e universal, ela não deixa de ser uma atividade, uma práxis. Ou seja, também a Filosofia pode ser compreendida a partir do conceito de disciplina técnica, uma vez que se encontra às voltas com a realização prática de fins bem precisos. Toda técnica é guiada pela unidade do escopo, ou seja, está imersa na razão em sentido prático (HUSSERL, 2009 a, § 3, p. 17). Sendo assim, do mesmo modo que a Filosofia é a disciplina teórica suprema, que oferece os princípios e normas de todas as disciplinas teóricas, a Ética será a disciplina técnica suprema que deverá submeter todas as disciplinas práticas, pois cabe a ela considerar o fim supremo e ideal na perspectiva do dever tomado de modo absoluto. Até mesmo a Filosofia deverá ser considerada a partir dessa subordinação.

[...] Toda ciência, mesmo a filosofia na qual todas as outras estão compreendidas, submete-se à ética, à rainha das disciplinas técnicas. Se o exercício do interesse teórico, se o pensamento e a pesquisa científica possuem um direito último, que deve ser valorizado como ramo da vida humana individual e social, então eles devem satisfazer os princípios éticos, a norma do dever absoluto (HUSSERL, 2009, a, § 3, p. 18. Itálicos do autor).

A mudança, portanto, parece radical. O interesse teórico que antes comandava interpreta-se, agora, como sendo apenas um tipo particular de interesse prático. Segundo Ferrarello (2010, p. 77), a razão lógica deixa de ter a primazia na medida em que depende da atividade produtiva da vontade, pois somente esta última pode trazer à existência aquilo que foi dado passivamente. Tudo se passa como se a razão teórica fosse incapaz de tomar consciência dos outros modos de consciência (passividade, sentimento, querer, etc.) que participam da constituição do mundo objetivo. Certo, a diferença essencial entre ciências teóricas e ciências práticas deve permanecer. Pode-se pensar a ideia de um conhecimento perfeito, que por sua vez corresponde à ideia de comunidade de pesquisadores motivados pelo interesse puramente teórico, bem como os resultados que surgem do trabalho crítico desses pesquisadores. Por outro lado, a função humana desse empreendimento é algo que vai além do próprio saber teórico. O indivíduo que assumiu o imperativo de uma vida dedicada à ciência não deixa de ser o membro de uma família, um cidadão, etc. e sendo assim, "deve inserir-se na ideia prática suprema de uma vida ética universal, da vida própria do indivíduo, bem como da vida da comunidade humana aberta" (HUSSERL, 1996, § 7, p. 46). 


\section{A forma racional de vida e a singularidade do sujeito ético}

Eis que chegamos ao núcleo de nossa exposição. A ideia de conhecimento perfeito não se separa da aspiração a uma forma racional de vida. A ideia de ciência como que se "personaliza", isto é, liga-se "a uma ideia de consciência 'vivente', que opera em função de um contínuo intercâmbio com a realidade" (FERRARELLO, 2010, p. 108). Pessoa e comunidade podem ser vistas em seu possível esforço para realizarem progressivamente valores autênticos e elevados de uma cultura, e mesmo da própria humanidade. Graças ao poder da vontade, pode-se aspirar a um agir racional, a uma forma racional de vida. O sujeito pessoal pode, então, engajar-se numa luta por um progresso ético continuado, que Husserl denomina ideal da razão (HUSSERL, 2014 a, p. 4).

Permanece, no entanto, a questão: o que é moral em sentido absoluto? Não é o saber ou a convicção de um sujeito que define a moralidade, sob a forma imperativa. A ciência é um valor, mas por que um determinado sujeito deve dedicar-se inteiramente a ela? A questão sobre o dever, ou aquilo que é devido absolutamente, não decorre de um saber, nem mesmo da convicção de que tal valor é digno de ser realizado. A esse respeito, a preocupação de Husserl não é com aquilo que é visado pela consciência moral, mas com o sentido moral da personalidade ética. Trata-se, como no caso da ciência, também de uma ideia, com a diferença de que, agora, a vontade se volta para o ideal de vida, uma vida guiada por normas racionais. Toda vida é prática na medida em que aspira a alguma coisa. Isto se dá até mesmo de modo instintivo ou como impulso. Mas a vontade racional ativa, ética, é algo que depende de uma constante luta pela saída da ingenuidade, do habitual, do "estar-aí" natural de todos nós. Um cientista que se devota à busca do verdadeiro juízo sobre sua atividade não se indaga sobre a ideia normativa presente em seu agir, em seu proceder, em seu conhecer.

Vimos que os conhecimentos científicos estão, mesmo que de modo inconsciente, buscando realizar a ciência como ideia de um conhecimento perfeito. Do mesmo modo, no agir humano voltado a qualquer atividade que aspira a um valor positivo, encontra-se em causa "uma regulação na vontade dirigida a uma legitimidade normativa realmente universal" (HUSSERL, § 49, 2009 a, p. 246). Cada ato que se realiza na vida pode ser visto a partir desta extensão, desta amplitude: a forma racional de vida. Mas, além da extensão, há outra coisa em jogo: o querer da subjetividade humana. Só a vontade pode produzir esta vida. É assim que o cientista que, nos limites de sua atuação, deseja o melhor sistema teórico possível, a melhor verdade possível; o artista, por sua vez, deseja o melhor entre as belezas que ele pode atingir. 
O melhor surge, portanto, como inimigo do bom, absorvendo tudo o que é parcial na escala dos valores. Na mais rigorosa atividade científica, não é apenas o valor de verdade que se encontra em causa, mas a vontade dirigida ao melhor, isto é, a vontade racional.

A forma de uma vontade racional se estende para todas as esferas da vida. Por quê? Porque ela está presente em todas as situações de fato que envolvem a intencionalidade. Não se pode falar em querer racional apenas parcial, como um juízo matemático que em nada irá afetar uma existência de modo direto, ou como um saber científico sobre a natureza, que diz respeito às verdades relacionadas a uma região do ser em particular. Tudo o que está relacionado ao âmbito da vontade, implica uma relação à sua verdade, mas nunca de modo apenas parcial. Por quê? Porque se trata de uma verdade inseparável do sujeito volitivo individual, único que poderia assumir um "eis o que é devido verdadeiramente". Compreendendo ou tomando consciência de sua unicidade, o sujeito da vontade se descobre numa situação paradoxal: é o "eu posso" sob a forma de responsabilidade, ou ainda, é o eu da iniciativa já inserido numa condição de não-poder: ele não pode ser substituído por nenhum outro sujeito. Diante de seu passado, de seu presente, e tendo em vista suas possibilidades futuras, o eu pessoal, situado no mundo a partir de múltiplas motivações, se descobre como liberdade comandada por um dever inalienável: fundar uma vontade normativa universal a partir de uma expressão singular (HUSSERL, 2009 a, § 49, p. 248).

Dito de outro modo, a vontade normativa universal não depende de uma adequação da existência humana em sua singularidade a algo puramente formal e, portanto, independente das escolhas de vida dos indivíduos. Não! É, antes, o contrário que se dá, pois, para Husserl, somente os motivos particulares de valor, tomados como matéria, podem oferecer um conteúdo à vontade racional. Em sentido puramente formal, o imperativo é o mesmo para cada um de nós. No entanto, cada um de nós poderá oferecer a este imperativo um conteúdo particular, tendo em vista sua inserção numa situação motivacional concreta. Tudo se passa como se, por diferentes que sejam as experiências humanas no tempo, o específico de uma existência pessoal pudesse realizar a vinculação da vontade em sua forma racional à vida individual. Temos, assim, dois movimentos, que se complementam, e que expressam o desafio de se vincular sentido ideal e vida temporal, graças ao reconhecimento de um dever absoluto, ou imperativo categórico de uma vida.

O primeiro movimento é este: o eu põe para si o dever de buscar a melhor vida possível. Ele assume, por sua vontade, a tarefa de ser uma pessoa que visa agir eticamente, numa espécie de relação, sempre reativada, com a forma racional de vida. Ao mesmo tempo 
(e este é o segundo movimento) tudo o que fazemos no tempo, da mais simples à mais complexa atividade, pode fazer cintilar a ideia de perfeição na realidade empírica e temporal. Comentando Fichte, o filósofo afirma:

\footnotetext{
Deus se revela de modo individual. Cada um de nós participa do ser divino e possui, por conseguinte, a sua própria ideia, aquela que constitui, do ponto de vista prático, o seu mais alto escopo de vida, a sua mais alta destinação. Ninguém pode trocar seu escopo de vida com aquele de um outro (HUSSERL, 2006, p. 83).
}

Eis a metafísica fenomenologicamente interpretada. A vida divina se compreende como manifestação do humano em suas expressões concretas, em suas escolhas de vida. Ao amar isto ou aquilo de modo verdadeiro e puro, o eu não é somente aquele que aspira a uma vida racional, sob a forma de autorrealização infindável, mas aquele que tomou consciência de que é imperativo lutar para que este valor se estenda à humanidade como um todo. Não se trata de dizer que eu e os "outros" devemos nos integrar ou nos subordinar a uma pura racionalidade formal, mas sim de compreender que a autêntica aspiração racional só é tal na medida em que busca preservar o que há de ideal, verdadeiro e original nas várias possibilidades de expressão humana. Negação inconsequente do universal? Em Husserl, explica Levinas, a universalidade não absorve o sujeito que a constitui. Separado deste eu que a constitui, "o universal é um modo abstrato de existência". O eu fenomenológico é um eu “arrancado à totalidade" (2010, p. 168-9).

\section{Conclusão}

Para concluir, digamos o seguinte. Aspirar à forma racional de vida não significa a absorção das singularidades por um logos impessoal, por uma totalidade, no sentido de Levinas. O que importa é o esforço e o compromisso, sempre renovados, de subjetividades humanas pessoais conferindo sentido e concretude à forma racional de vida. Pensamos, assim, que a tese supostamente inovadora da obra Introdução à ética, que consiste em afirmar que a própria Filosofia se subordina à Ética como rainha das disciplinas técnicas, não implica uma mudança radical no projeto transcendental da fenomenologia, mas sim a compreensão mesma deste projeto em sua unidade, ou seja, a partir do horizonte ético do qual ele emerge e para o qual Husserl sempre termina direcionando o nosso olhar, a despeito de sua obsessão em ver na Filosofia a ideia de um conhecimento absolutamente perfeito. 


\section{REFERÊNCIAS}

CENTI, B.- Il concetto di valore nelle Lezione di etica (1914) di Husserl : intrecci, nodi e senso della forma. In : CENTI, B./Gigliotti,G.- Fenomenologia della ragion pratica. L'etica di Edmund Husserl, Napoli : Bibliopolis, 2004 (p. 255-325).

FERRARELLO, S.- Il progetto etico e l'idea di scienza in Husserl. Padova: libreria universitaria.it Editore, 2010.

HUSSERL, E.- Logique formelle et logique transcendentale. Trad. Suzanne Bachelard, Paris : PUF, 1996.

HUSSERL, E.- De la synthèse passive. Trad. Bruce Bégout e Jean Kessler, Grenoble : Jérôme Millon, 1998.

HUSSERL, E.- Fichte e l'ideale di umanità. Tre lezione. Trad. Francesca Rocci; Pisa: Edizioni ETS, 2006.

HUSSERL, E.- Leçons sur l'éthique et la théorie de la valeur. Trad. Philippe Ducat, Patrick Lang e Carlos Lobo, Paris: PUF, 2009.

HUSSERL, E.- Introduzione all'etica. Trad. Nicola Zippel, Roma-Bari: Laterza, 2009 a.

HUSSERL, E.- Investigações Lógicas. Prolegômenos à Lógica Pura. Trad. Diogo Ferrer, Rio de Janeiro: Forense, 2014.

LEVINAS. E.- En découvrant l'existence avec Husserl et Heidegger. Paris : Vrin, 2010.

MURALT, A.- L'idée de La phénoménologie. L'exemplarisme husserlien. HildesheimZürich-New York : Georg Olms Verlag, 1987. 